\title{
Copper on Activated Carbon for Catalytic Wet Air Oxidation
}

\author{
Nora Dolores Martinez*, Rosa Beatriz Venturini*, \\ Hugo Soé Silva*, José Eduardo González*, Ana María Rodríguez* \\ Instituto de Ingeniería Química, Universidad Nacional de San Juan, \\ Av. Libertador San Martín, 1109, Oeste, 5400 San Juan, Argentina
}

Received: December 11, 2007; Revised: February 20, 2009

\begin{abstract}
Textile industry is an important source of water contamination. Some of the organic contaminants cannot be eliminated by nature in a reasonable period. Heterogeneous catalytic wet air oxidation is one of the most effective methods to purify wastewater with organic contaminants. In this work, catalysts based on copper supported on activated carbon were synthesized. The activated carbons were obtained from industrial wastes (apricot core and grape stalk) of San Juan, Argentina. These were impregnated with a copper salt and thermically treated in an inert atmosphere.

Analysis of specific surface, pore volume, $p_{z c}$, acidity, basicity and XRD patterns were made in order to characterize the catalysts. The catalytic activity was tested in the oxidation of methylene blue (MB) and polyvinyl alcohol (PVA) in aqueous phase with pure oxygen. Reaction tests were carried out in a Parr batch reactor at different temperatures, with a $0.2 \mathrm{MPa}$ partial pressure of oxygen. The amount of unconverted organics was measured by spectrophotometry.

Higher temperatures were necessary for the degradation of PVA compared to those for methylene blue.
\end{abstract}

Keywords: activated carbon, heterogeneous catalysis, wet oxidation

\section{Introduction}

Textile industry is an important source of water contamination. Some of the organic contaminants can not be eliminated by nature in a reasonable period. The methods to abate those contaminants are of physicochemical character: incineration, chemical oxidation and wet air oxidation ${ }^{1}$. All of them result inappropriate to process large amounts of wastewaters due to their high costs. The last one seems to be a good alternative, but requires high temperatures and pressures to make the reaction possible because of the high activation energy involved ${ }^{2}$. Therefore, the possibility of catalyzing the reaction seems to be a good option. Catalytic Wet Oxidation is an excellent technological alternative because it allows destroying the organic contaminants at lower temperature and pressure due to the minor activation energy of the catalyzed reaction ${ }^{2}$. Some transition metals such as copper, platinum and palladium have been tested as catalytic agent with good results ${ }^{2,3}$. Today, they are used in homogeneous catalysis, in some industrial technologies ${ }^{4,5}$, but in these processes it is necessary to incorporate an active agent recuperation system. So, the heterogeneous catalysis is a good alternative because the catalyst can be separated easily from the treated water. These technologies use copper, palladium or silver supported over titaniazirconia $^{4,5,6}$. Some studies were reported about the use of alumina or ceria - alumina supports ${ }^{1,7}$.

Activated carbon appears as a good catalytic support, because of its excellent textural and physicochemical properties ${ }^{8}$. The use of activated carbon as a support, leads to lower operation costs because of the less expensive chemicals involved and because it can be obtained from low cost materials (agricultural industrial wastes).

Almost any carbonaceous material, with high carbon content and low proportion of inorganic components, can be used as precursor for the preparation of activated carbons ${ }^{9}$. In this work, activated carbons were obtained from industrial wastes (apricot core and grape stalk) of San Juan, Argentina. They were prepared following the protocol described in previous works ${ }^{10,11}$. After that, the different carbons were submitted to catalyst preparation routines, that is, impregnation with cupric nitrate as a precursor salt followed by thermal treatment at
$830 \mathrm{~K}^{[12]}$. These catalysts were tested for the degradation of methylene blue and polyvinyl alcohol as probe molecules.

\section{Materials and Methods}

\subsection{Preparation of catalysts}

Two different types of activated carbons were produced for this study. One of them was obtained from apricot stone and the other from grape stalk. The synthesis protocol included:

\subsubsection{Carbonization}

Samples were pyrolized in a batch process using a retort-like stainless steel reactor, in a nitrogen inert atmosphere, with a heating rate of $1.4 \mathrm{~K} / \mathrm{min}$, from room temperature up to $773 \mathrm{~K}$, and keeping the final temperature for 2 hours $^{13}$. A K-type thermocouple and a Microomega CN77000 Series digital temperature controller were used to set and control the temperature of the sample.

\subsubsection{Activation}

Samples were heated in a stainless steel reactor using an electric oven. The temperature was set and controlled using a K-type thermocouple and a digital temperature controller ${ }^{10,11,14}$. The samples were heated up at a $5 \mathrm{~K} / \mathrm{min}$ rate, from room temperature to $1123 \mathrm{~K}$ in a $300 \mathrm{~mL} / \mathrm{min} \mathrm{N}_{2}$ flow. When the final temperature was reached, the $\mathrm{N}_{2}$ current was substituted by steam water as activating agent, at a flowing rate of $1.7 \mathrm{~g} \cdot \mathrm{g}^{-1}$ of carbonized matter per hour. The activation treatment lasted 105 minutes.

\subsubsection{Impregnation}

Catalysts were formulated using a solution of $\mathrm{Cu}\left(\mathrm{NO}_{3}\right)_{2} \cdot 3 \mathrm{H}_{2} \mathrm{O}$ $(5 \mathrm{wt} .(\%) \mathrm{Cu})$ as a precursor of the active agent because of its water solubility, lower cost, and lack of poisonous elements. Activated carbons from apricot stone and grape stalk were used as supports. 
There are two well known methods of loading the metal precursor on the support: incipient wetness impregnation and soaking method. In this case, the second one was used; the activated carbons were soaked in a copper nitrate solution for 4 days under agitation until the equilibrium was reached. The ratio solid/solution (weight base) was equal to 6 . The impregned solids were filtered and scurried during 24 hours. Then, they were dried at $378 \mathrm{~K}$ for 24 hours $^{12}$.

\subsubsection{Thermal treatment}

The objective of this step is to transform the copper salt (cupric nitrate) in copper oxides, which are the active catalytic agents. The high temperature used descomposes the nitrate releasing nitrogen oxides. The reactor must work in a nitrogen atmosphere to avoid the combustion of the support.

The catalysts were treated in the activation reactor, at $830 \mathrm{~K}$ for 18 hours. After that, a nitrogen flow was maintained until the reactor reached room temperature ${ }^{12}$.

\subsection{Characterization}

Nitrogen adsorption-desorption isotherms were performed using an Autosorb-1 (Quantachrome) equipment. Samples of $0.100 \mathrm{~g}$ were oven-dried at $378 \mathrm{~K}$ during 24 hours and outgassed at $473 \mathrm{~K}$ under vacuum for 10 hours. The final pressure was less than $10^{-4}$ mbar. Textural parameters were derived from adsorption data. The specific BET surface area was estimated ${ }^{15}$. The specific total pore volume $\left(\mathrm{V}_{\mathrm{T}}\right)$ was determined from the adsorption isotherm at the relative pressure of 0.99 , converted to liquid volume assuming a nitrogen density of $0.808 \mathrm{~g} . \mathrm{cm}^{-3}$. The specific micropore volume $\left(\mathrm{V}_{\mathrm{DR}}\right)$ was determined using the Dubinin-Radushkevich model ${ }^{16}$. The pore size distribution (PSD) was analyzed using the BJH method ${ }^{17}$.

Acidity and basicity determinations of the support were made by titrating the acid sites with a strong basic solution and the basic sites with a strong acid solution, following the protocol detailed by Noh and Schwarz ${ }^{18}$.

In order to determine the net surface charge of the supports, the measurement of the point of zero charge $\left(\mathrm{P}_{\mathrm{ZC}}\right)$ was carried out by the mass titration method following the procedure detailed by Noh and Schwartz ${ }^{18}$.

Studies of $\mathrm{X}$ ray diffraction $(\mathrm{XRD})$ patterns were recorded at room temperature using a Rigaku diffractometer operated at $30 \mathrm{kV}$ and $20 \mathrm{~mA}$, employing $\mathrm{Ni}$-filtered $\mathrm{Cu} \mathrm{K} \alpha$ radiation $(\lambda=0.15418 \mathrm{~nm})$. The crystalline phases were identified employing standard spectra software.

\subsection{Reaction test}

The organics used as probe molecules in catalytic oxidation tests were Methylene Blue (MB) and Polyvinyl Alcohol (PVA). The reaction tests were carried out in a $1 \mathrm{~L}$ Parr batch reactor. The oxidant was high purity oxygen. Nitrogen was used when an inert atmosphere was necessary.

In the PVA catalytic oxidation reaction, temperatures between 398 and $438 \mathrm{~K}$ were used. Temperatures between $323 \mathrm{~K}$ and $353 \mathrm{~K}$ were employed for MB. In every single assay $200 \mathrm{mg}$ of catalyst were used. In all cases, the concentration of organic compound was $500 \mathrm{mg} . \mathrm{L}^{-1}$. The organic solution $(500 \mathrm{~mL})$ was introduced into the reactor, and a $\mathrm{N}_{2}$ partial pressure of $0.2 \mathrm{MPa}$ was maintained until the operation temperature was reached. After that, the oxygen was introduced in the reactor at a $0.2 \mathrm{MPa}$ partial pressure.

Some tests were carried out in an $\mathrm{O}_{2}$ atmosphere without catalyst to detect the non catalytic oxidation phenomenon. Other tests, at the lowest temperatures, were carried out in $\mathrm{N}_{2}$ atmosphere with catalyst to detect the adsorption phenomenon.
Samples were taken at different times during 2 hours. The unconverted organics concentration was measured in a 4001-Wayers UV-visible spectrophotometer. The monitoring of MB concentration was made directly, but to detect PVA, it was necessary to add a complex with I-KI- $\mathrm{H}_{3} \mathrm{BO}_{3}$.

\section{Results and Discusion}

\subsection{Characterization}

Nitrogen adsorption-desorption isotherms for the supports and catalysts are shown in Figures 1 and 2. The textural parameters modelled from the adsorption data are summarized in Table 1.

Both catalysts present lower surface area and pore volume compared to that of the corresponding support. This is mainly due to a pore blocking effect, especially micropores, which is evident from the analysis of the uptake at low relative pressures in the adsorptiondesorption isotherms for the catalysts compared to the supports.

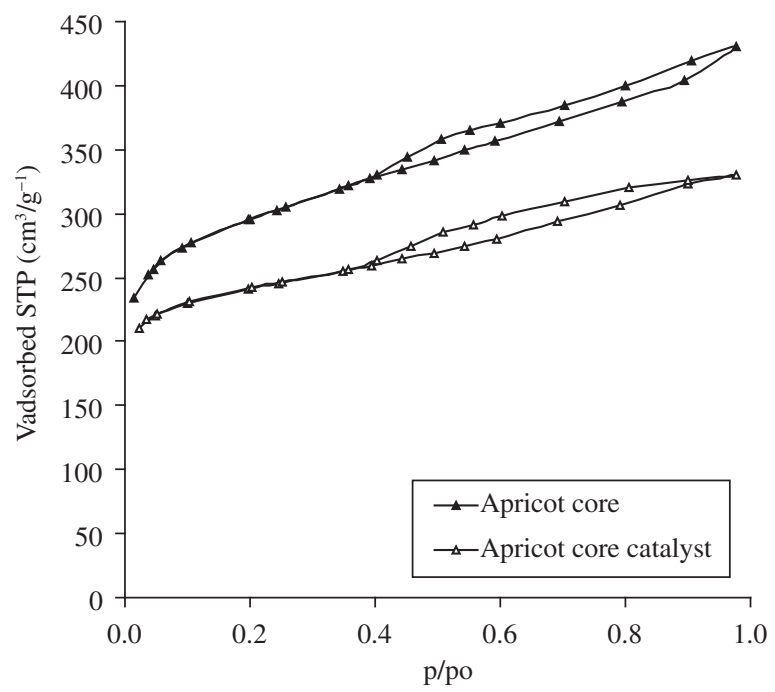

Figure 1. Nitrogen adsorption-desorption isotherms (77 K) for apricot core AC support and catalyst.

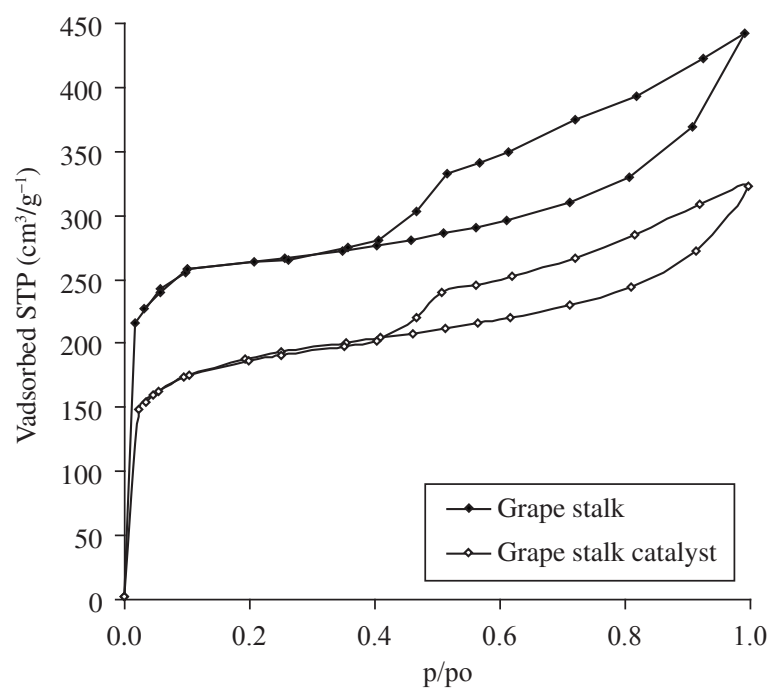

Figure 2. Nitrogen adsorption-desorption isotherms ( $77 \mathrm{~K}$ ) for grape stalk AC support and catalyst. 
Table 1. Textural parameters.

\begin{tabular}{lccc}
\hline \multicolumn{1}{c}{ Sample } & BET surface area $\left(\mathrm{m}^{2} \cdot \mathrm{g}^{-1}\right)$ & $\begin{array}{c}\text { Pore volume }(\mathrm{VT}) \\
\left(\mathrm{cm}^{3} \cdot \mathrm{g}^{-1}\right)\end{array}$ & $\begin{array}{c}\text { Specific micropore volume } \\
\left(\mathrm{V}_{\mathrm{DR}}\right)\left(\mathrm{cm}^{3} \cdot \mathrm{g}^{-1}\right)\end{array}$ \\
\hline Apricot core AC & 1002 & 0.6641 & 0.4495 \\
Apricot core AC Catalyst & 806 & 0.5106 & 0.3719 \\
Grape stalk AC & 846 & 0.6664 & 0.3919 \\
Grape stalk AC Catalyst & 618 & 0.4862 & 0.2851 \\
\hline
\end{tabular}

The micropore volume and surface area for the activated carbon from apricot core catalyst is higher than that obtained from grape stalk, although the total pore volume are similar for both materials.

The isotherms corresponding to both catalysts present a hysteresis loop. The uptake at high pressure rises significantly for grape stalk, which indicates a considerable presence of mesoporous. The BJH pore size distribution (Figures 3 and 4) shows important mesoporosity in the range of 40-90 A for both catalysts, specially in grape stalk AC, in agreement with its hysteresis loop.

Figures 5 and 6 show the curves obtained in the point of zero charge determinations using the mass titration method. All these results, $\mathrm{pH}$, acidity, basicity and $\mathrm{p}_{\mathrm{zc}}$, demonstrate that the surface of both supports are strongly basic (Table 2).

The X Ray diffraction patterns for both catalysts are shown in Figures 7 and 8 . The profiles obtained show that the main oxidized metal compound corresponds to $\mathrm{CuO}$. The signals of $\mathrm{Cu}_{2} \mathrm{O}$ and $\mathrm{Cu}$ are also present in the spectra, specially the last one. The presence of $\mathrm{CuO}$ was expected because the metal appears as divalent ion in the precursor salt. The reduced species $\left(\mathrm{Cu}^{+}\right.$and $\left.\mathrm{Cu}^{0}\right)$ could be produced by the reducing action of the carbon surface during the thermal treatment at high temperatures.

\subsection{Reaction test}

The test reaction results are shown as \% remnant of Methylene Blue or Polyvinyl Alcohol, defined as:

$$
\% \text { remnant }=\frac{\text { remnant organic concentration }}{\text { initial organic concentration }} \times 100
$$

The system response for catalytic oxidation of MB with apricot core AC as catalyst support, is shown in Figure 9. The results of the catalytic oxidation of MB using activated carbon of grape stalk as support can be observed in Figure 10. Reaction temperatures between 323 and $353 \mathrm{~K}$ were used in the experimental program. In both cases (apricot core and grape stalk) the behavior of the catalysts was similar, with an increase of the catalytic activity when the temperature rises, as it was expected.

In Figures 11 and 12, the results of the oxidation reaction of PVA for both catalysts are shown. While the abatement of PVA with the apricot core based catalyst is important at $398 \mathrm{~K}$, the one corresponding to grape stalk based catalyst is negligible. At the highest tested temperature, $438 \mathrm{~K}$, the catalytic activities were similar, although the one corresponding to apricot core based catalyst was slightly higher.

Figures 9 and 11 also show the resulting curves of an assay of non catalytic oxidation, using oxygen without catalyst, at the maximum reaction temperature, in each case. They show that there is no abatement of MB or PVA due to the non catalized reaction at the tested temperatures.

The adsorption, which is higher at lower temperatures is negligible in comparison with that of the catalytic reaction. Results of the adsorption of MB and PVA (using catalyst in a nitrogen atmosphere) at the lowest tested temperature are presented in Figures 9 and 10.

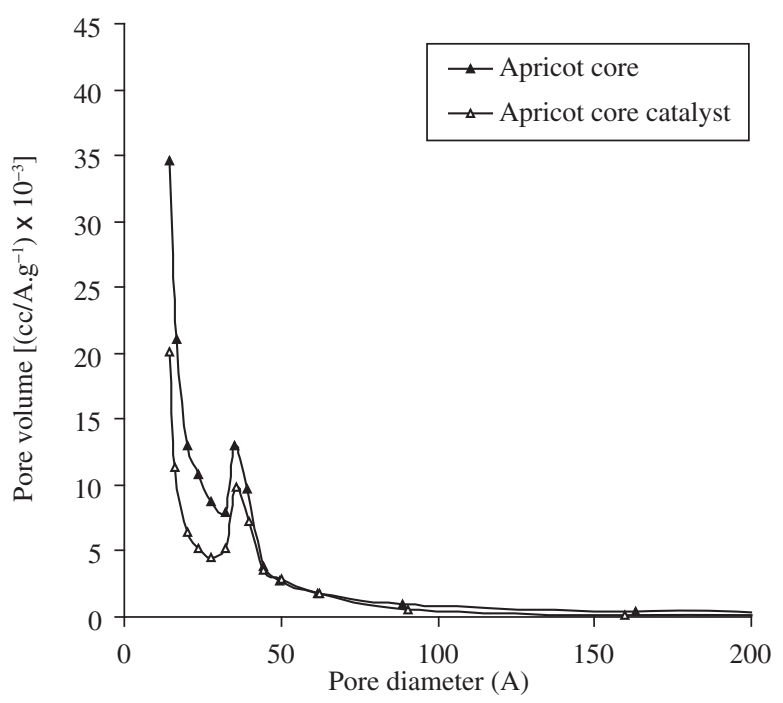

Figure 3. Pore size distribution for apricot core AC support and catalyst.

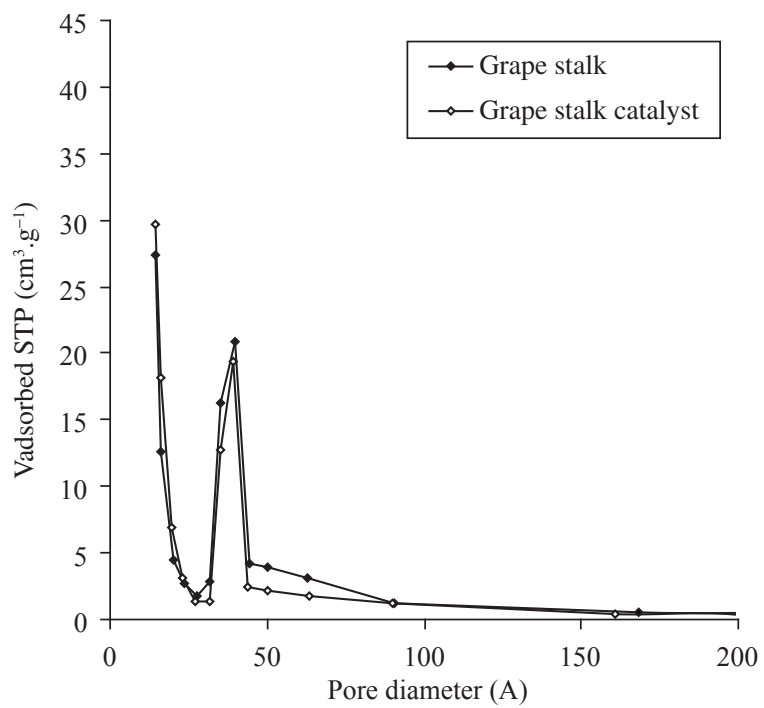

Figure 4. Pore size distribution for grape stalk AC support and catalyst.

If textural parameters of both catalytic formulations are compared, it can be seen that, although both of them are quite similar, the apricot core coal has a slightly higher surface area and pore volume, with more presence of micropores. This small difference could explain the slightly higher catalytic activity observed for the apricot core AC based catalyst compared to that of grape stalk based catalyst for the oxidation of MB and for PVA 
Table 2. Physicochemical characteristics of the activated carbon supports.

\begin{tabular}{crccc}
\hline Support & $\mathrm{pH}$ & Acidity $\left(\mathrm{mmol} . \mathrm{g}^{-1}\right)$ & ${\text { Basicity }\left(\mathrm{mmol}_{\mathrm{g}} \mathrm{g}^{-1}\right)}$ & $\mathrm{pH} \mathrm{PZC}_{\mathrm{PC}}$ \\
\hline Apricot core & 9.6 & 0.22 & 0.75 & 10.2 \\
Grape stalk & 10.3 & 0.3 & 1.3 & 12.0 \\
\hline
\end{tabular}

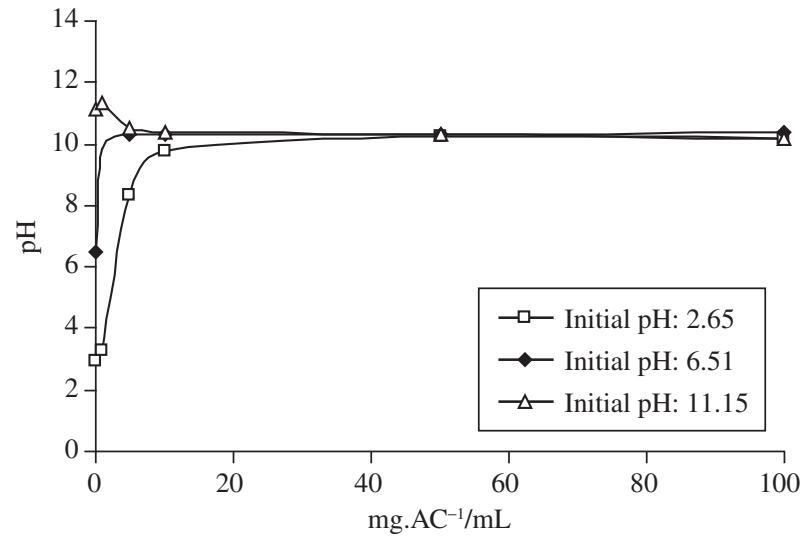

Figure 5. Mass titration of apricot core activated carbon.

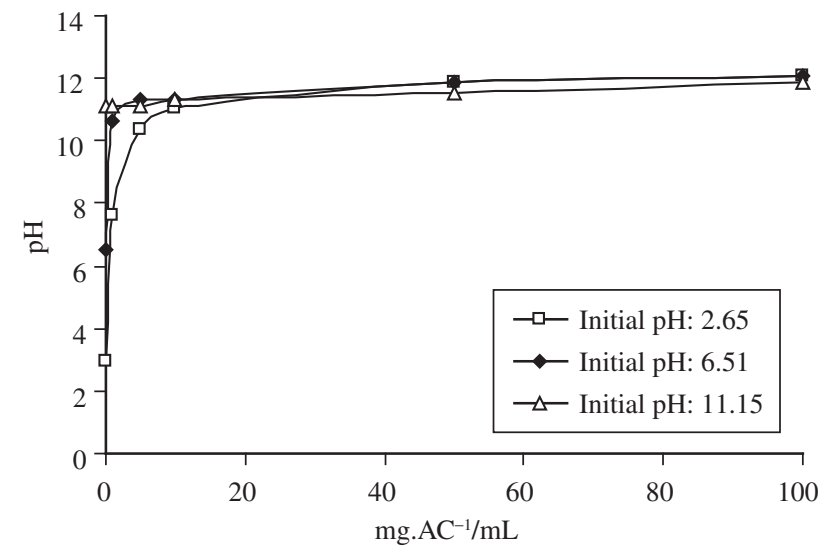

Figure 6. Mass titration of grape stalk activated carbon.

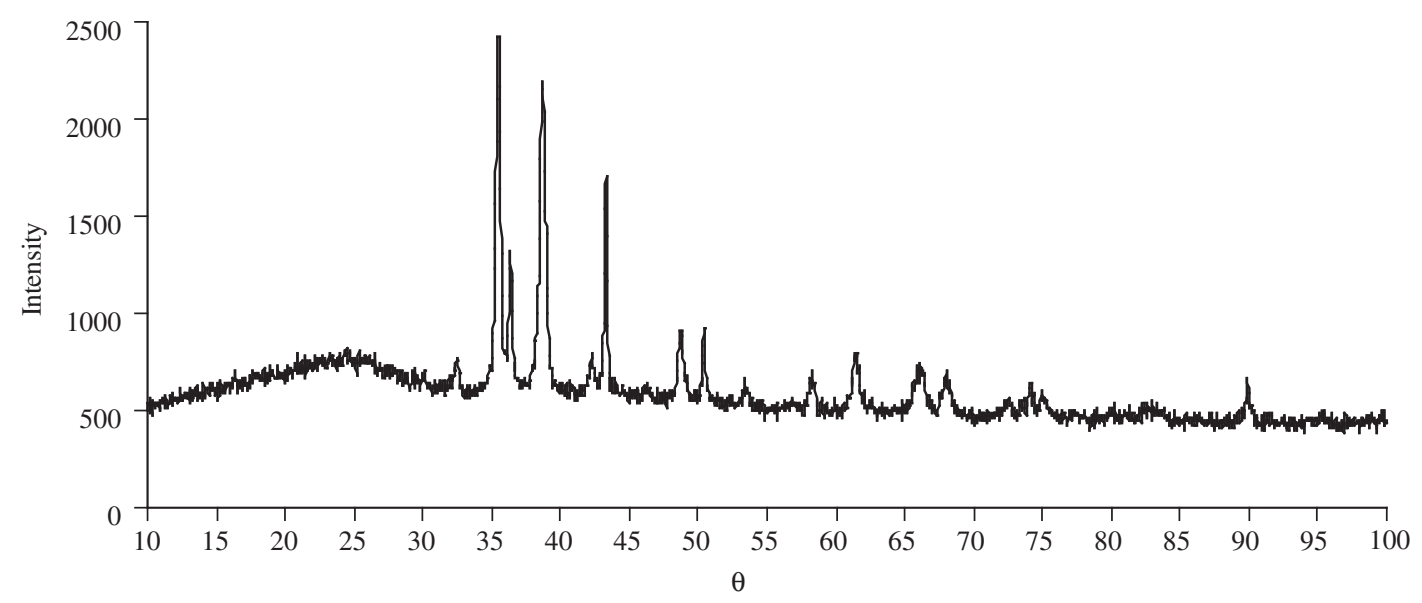

Figure 7. XRD pattern of apricot core activated carbon.

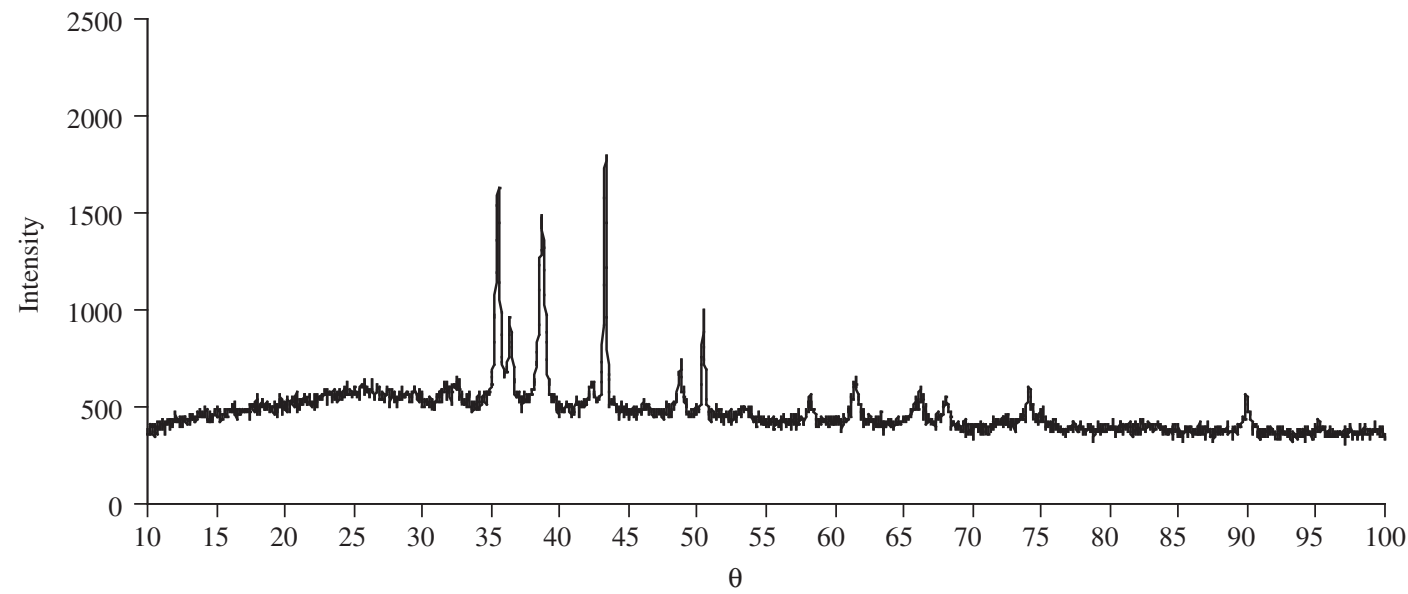

Figure 8. XRD pattern of stalk grape activated carbon. 


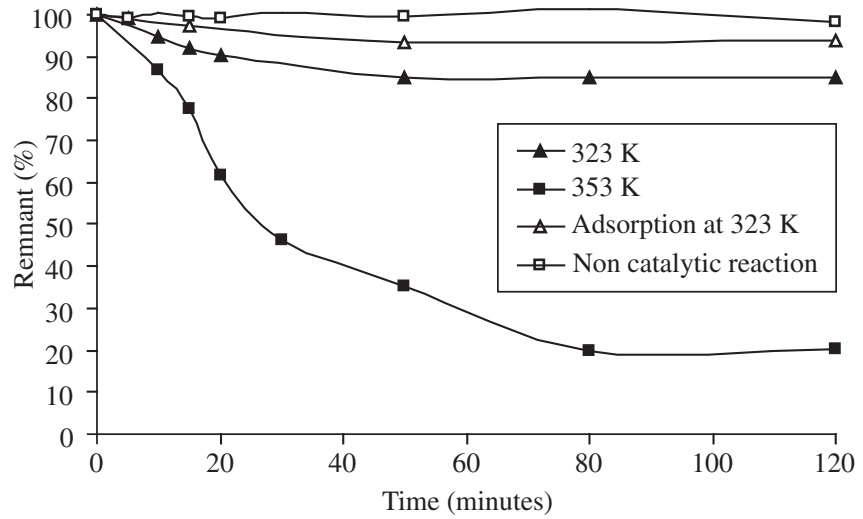

Figure 9. MB reaction test response with apricot core activated carbon.

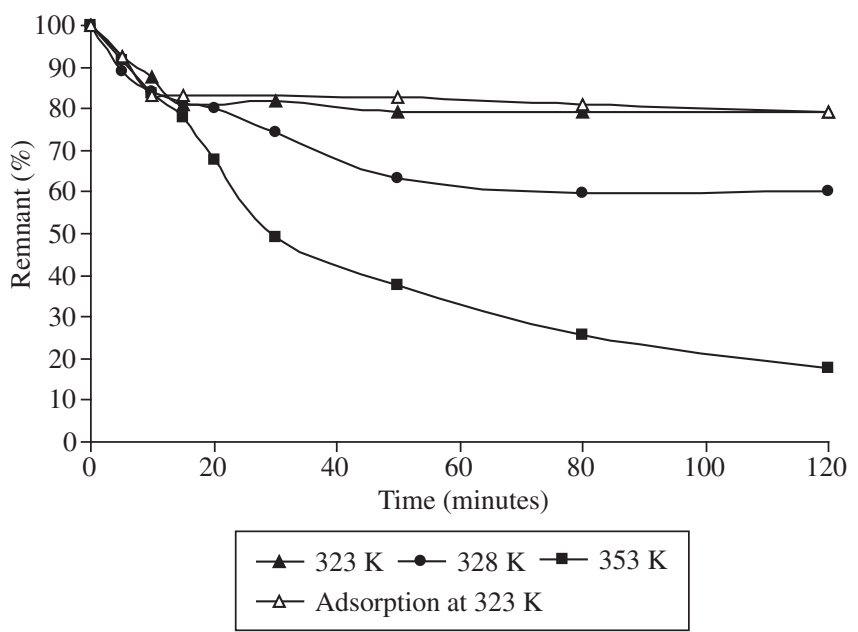

Figure 10. MB reaction test response with grape stalk activated carbon.

\section{Conclusions}

The use of wastes of agricultural industries to obtain activated carbon, allows to transform those materials into higher value added products.

The oxidation of PVA and MB water solutions can be carried out efficiently by means of cupric oxide catalysts supported on activated carbon, obtained from raw material of different origins.

Synthesized catalysts show a significant activity at $353 \mathrm{~K}$ for MB, and the behavior is similar in both catalytic formulations.

Higher temperatures are necessary for the oxidation of PVA, with the two catalysts tested, compared with those necessary to oxidize MB. The behavior is similar for both catalytic formulations, for each probe molecule.

As surface chemistry might play a key role in catalytic reactions, additional studies to determine the surface chemical groups are being carried out to confirm this.

\section{Acknowledgements}

The authors gratefully acknowledge the financial support received from the Universidad Nacional de San Juan.

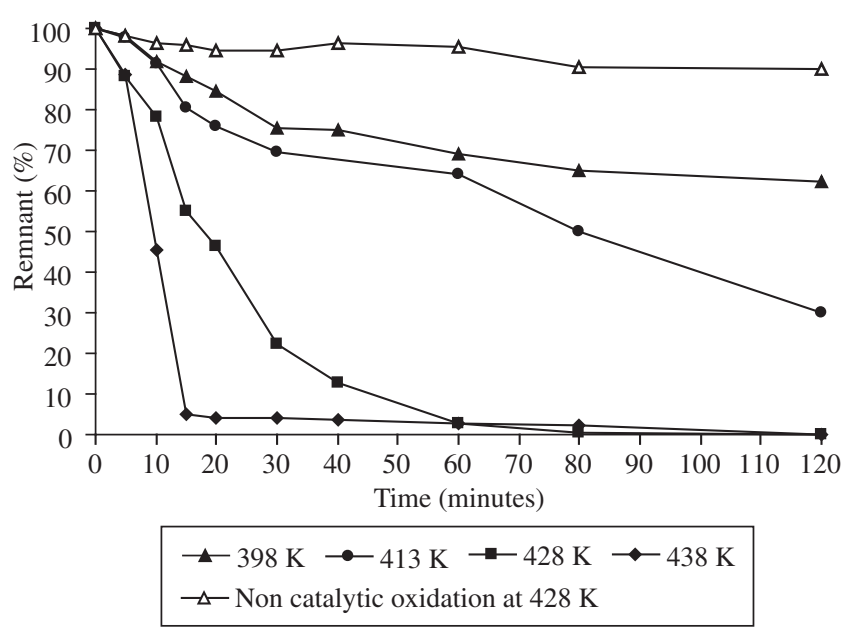

Figure 11. PVA reaction test response with apricot core activated carbon.

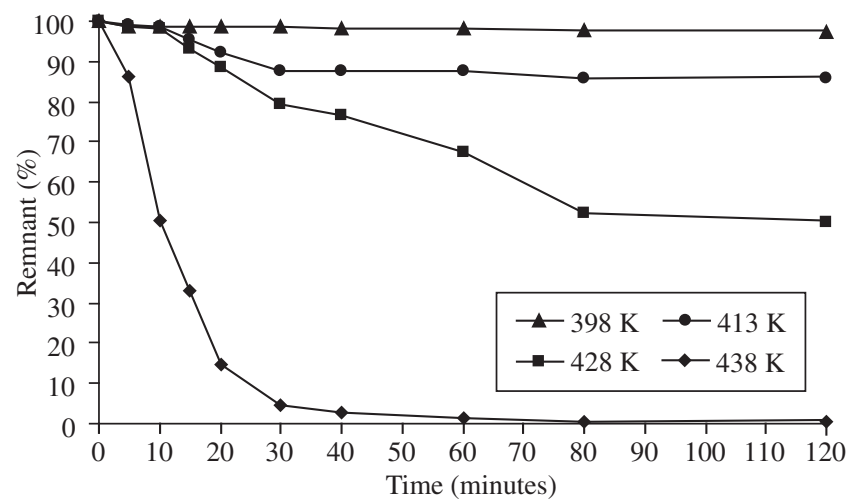

Figure 12. PVA reaction test response with grape stalk activated carbon.

\section{References}

1. Bhargava S, Tardío J, Prasad J, Föger K, Akolekar D, Grocott S. Wet oxidation and catalytic wet oxidation. Industrial \& Engineering Chemical Research. 2006; 45(4):1221-1258.

2. Lei L, Hu X, Chen G, Porter JF, Yue PL. Wet air oxidation of desizing wastewater from textile industry. Industrial \& Engineering Chemical Research. 2000; 39(8):2896-2901.

3. Mantzavinos D, Hellenbrand R, Livingston AG, Metcalfe IS. Catalytic wet air oxidation of polyethylene glycol. Applied Catalysis B: Environmental. 1996; 11(1): 99-119.

4. Kolaczkowski ST, Plucinski P, Beltran FJ, Rivas FJ, Mc Lurgh DB. Wet air oxidation: a review of process technologies and aspects in reactor design. Chemical Engineering Journal 1999; 73(2):143-160.

5. Luck F. Wet air oxidation: past, present and future. Catalysis Today. 1999; 53(1):81-91.

6. Pintar A. Catalytic process for the purification of drinking water and industrial effluents. Catalysis Today. 2003; 77(4):451-465.

7. Fortuny A, Bengoa C, Font J, Catells F, Fabregat A. Water pollution abatement by catalytic wet air oxidation in a trickle bed reactor. Catalysis Today. 1999; 53(1):107-114. 
8. Rodríguez-Reinoso F. The role of carbon materials in heterogeneous catalysis. Carbon. 1998; 36(3):159-175.

9. Rodríguez-Reinoso F. Carbons. In: Schüth F, Sing K, Weitkamp J, editors. Handbook of porous solids. Germany: Wiley-VCH; 2002. p. 1766-1827.

10. Deiana A, Petkovic L, Silva H, Aguilar E, Sardella M, Venturini R. Residuos y subproductos para la obtención de briquetas de Carbón Activado. Proceedings of the VI Curso-Taller Iberoamericano de Adsorbentes y Catalizadores para la Protección Ambiental, Redes Temáticas VC y VC - CYTED; Caracas; 2002, abril 9. p. 9.

11. Deiana AC, Granados D, Petkovic LM, Sardella MF, Silva HS. Use of grape must binder to obtain activated carbon briquettes. Brazilian Journal of Chemical Engineering. 2004; 21(4):585-591.

12. Hu X, Lei L, Chu H, Yue P. Copper: activated carbon as catalyst for organic wastewater treatment. Carbon. 1999; 37(4):631-637.
13. Rodríguez-Valero M, Martínez-Escandell M, Molina-Sabio M, Rodríguez-Reinoso $\mathrm{F}$. $\mathrm{CO}_{2}$ activation of olive stones carbonized under pressure. Carbon. 2001; 39(2): 320-323.

14. Tancredi N, Cordero T, Rodríguez-Mirasol J, Rodríguez J. Activated carbon from Uruguayan eucalyptus wood. Fuel. 1996; 75(15):1701-1706.

15. Brunauer S, Emmett P, Teller E. Adsorption of gases in multimolecular layers. Journal of the American Chemical Society 1938; 60(2):309-319.

16. Rouquerol F, Rouquerol J, Sing K. Adsorption by powders \& porous solids: principles, methodology and applications. London: Academic Press; 1999.

17. Greg S, Sing K. Adsorption, Surface area and Porosity. San Diego: Academic Press, Harcoury Brace \& Co. Publishers; 1982.

18. Noh J, Schwarz J. Effect of $\mathrm{HNO}_{3}$ treatment on the surface acidity of activated carbons. Carbon. 1990; 28(5): 675-682. 